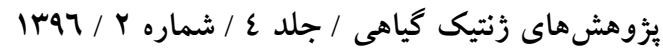

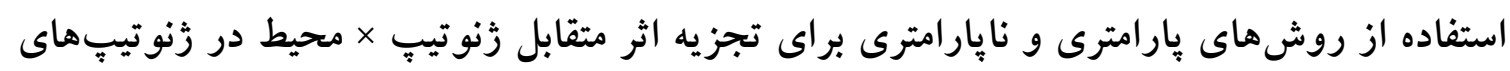
كندم نان

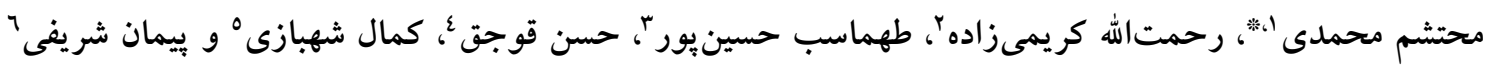

1- استاد، موسسه تحقيقات كشاورزى ديم كشور - سازمان تحقيقات، آموزش و ترويج كشاورزى، كجّاران

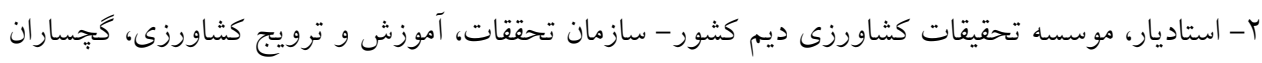

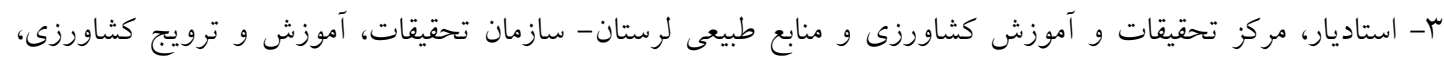
خرمآباد ع- مربى، مركز تحقيقات و آموزش كشاورزى و منابع طبيعى گلستان - سازمان تحقيقات، آموزش و ترويج كشاورزى، كنبد

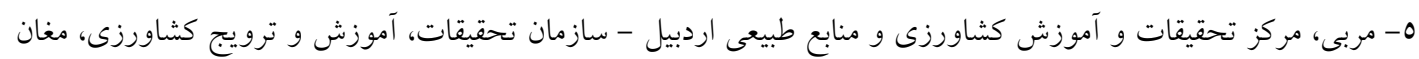

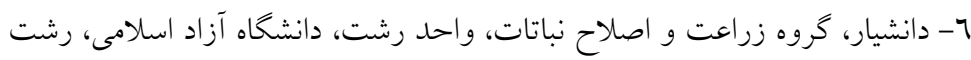

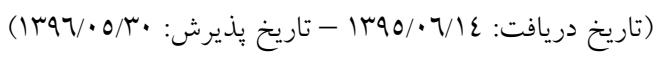

برنامههاى اصلاحى معمولاً مبتنى بر ارزيابى تظاهر موفق زنوتيبها در مناطق و سالهاى مختلف بويزه در مراحل نهايى

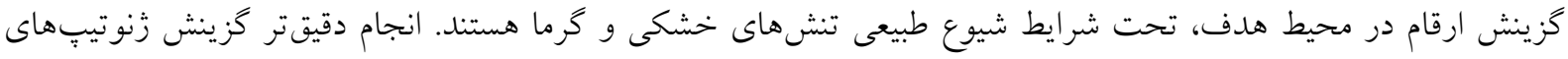

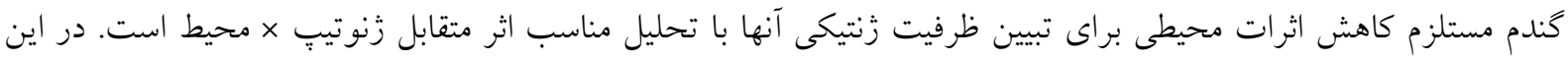

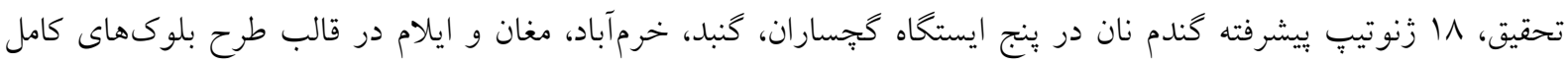

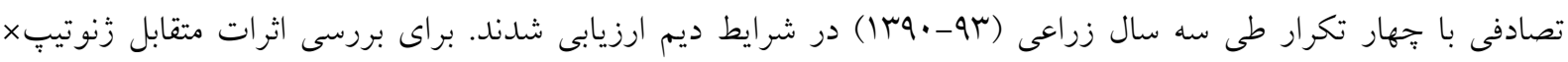

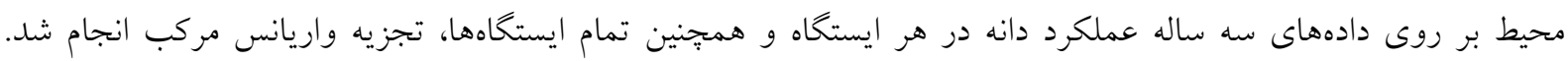

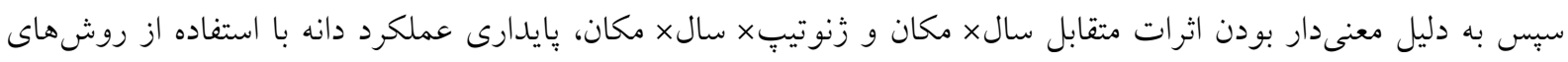

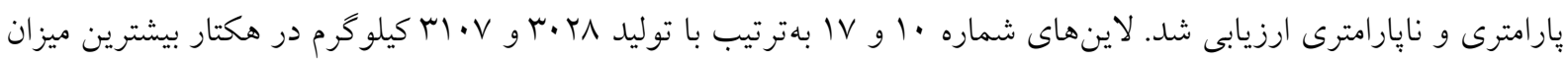
توليد دانه را داشتند. بر اساس آمارههاى بِارامترى: CV ل

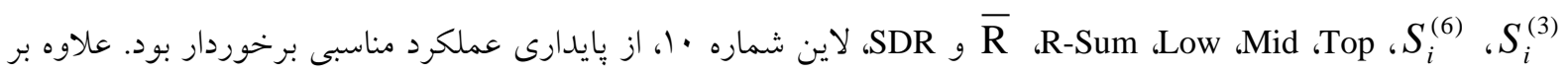

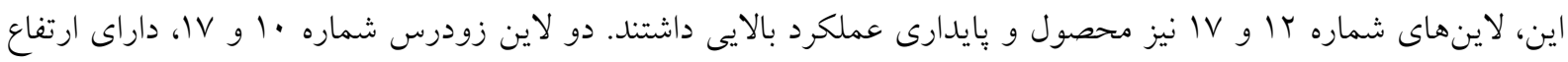
بوته مطلوب و وزن هزار دانه نسبتاً زيادى بودند. وازگَان كليدى: اصلاح، ساز كارى، پايدارى، ديم، خشكى، گرما 
اجراى آزمايشات افزايش مى يابد. در حالى كه اطلاعات

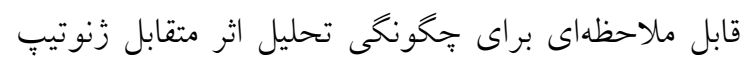
در محيط در دسترس قرار مى گيرد. فراهم ساختن بايخاه اطلاعاتى مبتنى بر اطلاعات دقيق، توليدكنند كان را قادر به دريه

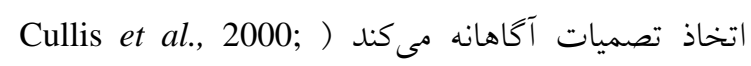

.(Baenziger et al., 2006; Roozeboom et al., 2008 آزمايشهاى جند منطقهاى بهترين ابزار براى فهم واكنش

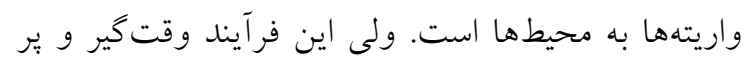

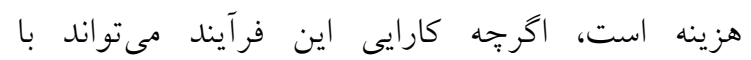

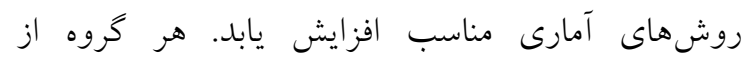

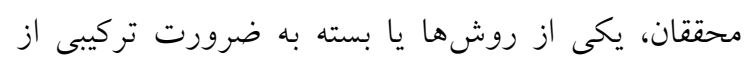

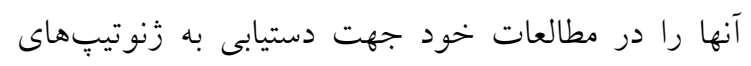
برمجصول و بِايدار به كار بردهاند.

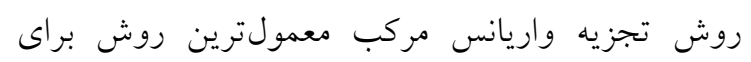
شناسايى وجود اثر متقابل زنوتيب × محيط در آزمايشات

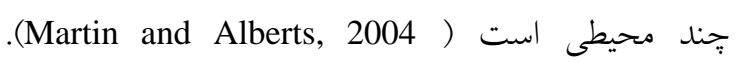

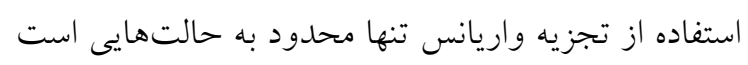

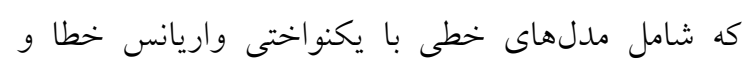

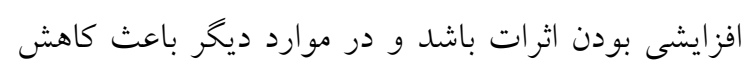

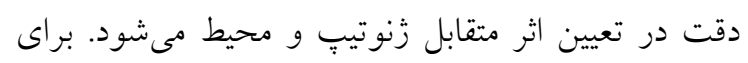

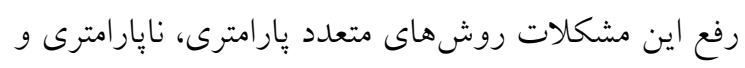

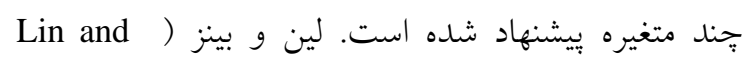

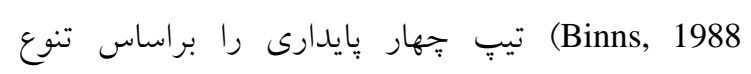

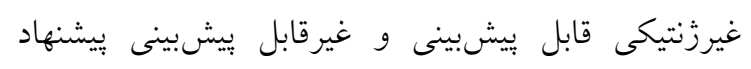

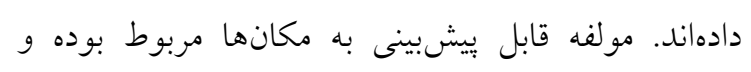
مولفه غير قابل بيشبينى با سالها مرتبط است.

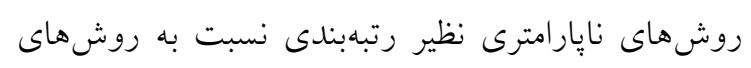

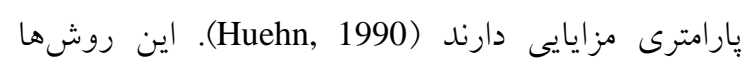

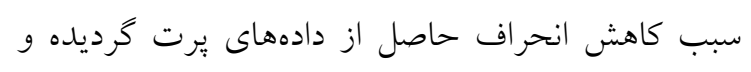
به بيش فرضهاى موجود در توزيع دادهها نيازى ندارند.

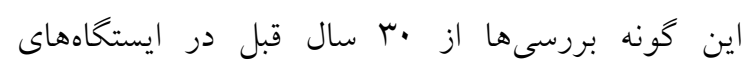

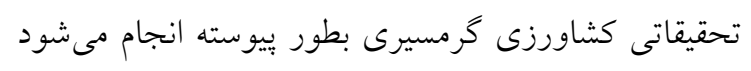

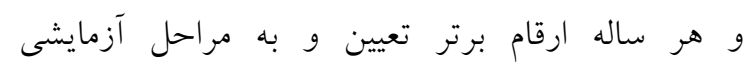

خشكى و گرما عوامل كليدى تاثير كذار بر كاهش ظرفيت عملكرد كياهان زراعى هستند (Barnabas et al., 2008). عملكرد گندم در اغلب مناطق گرمسير و نيمه گرمسير به زيه

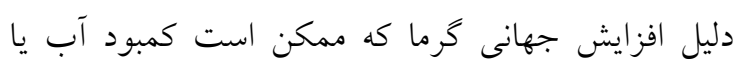
خشكى را تشديد نمايد، كاهش خواهد يافت ( Ortiz et

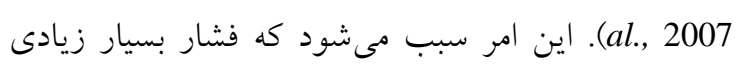

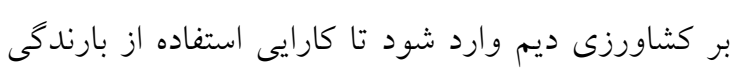
و عناصر غذايى بهبود يابد (Neil et al., 2011).

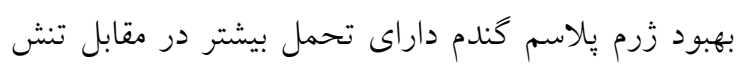



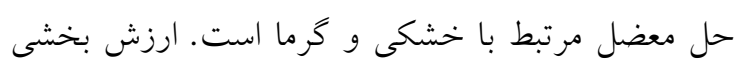

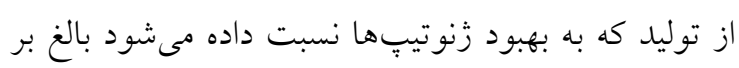

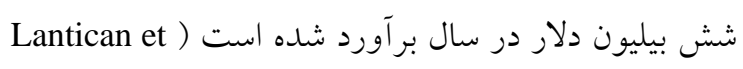

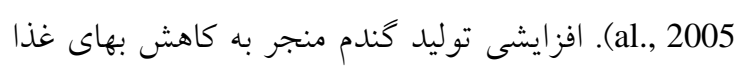

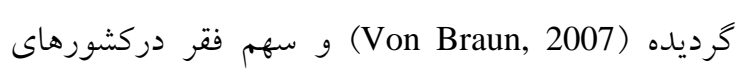

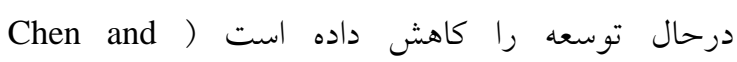

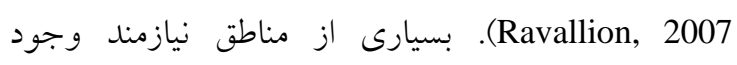

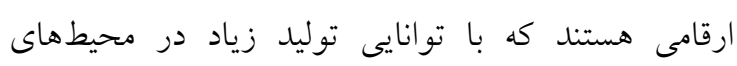

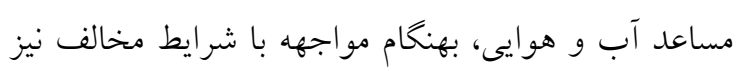
توليد بايدارى داشته باشند (بang et al., 2002).

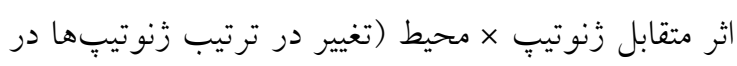

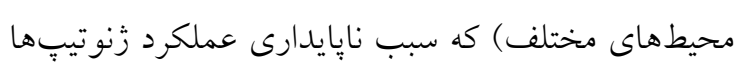

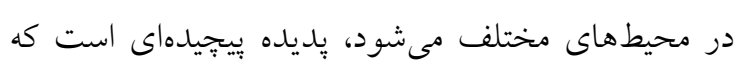

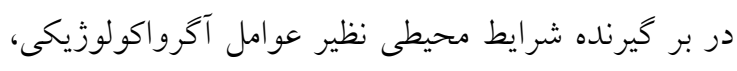

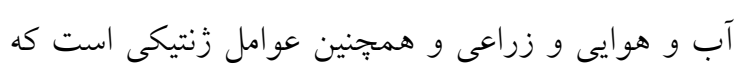

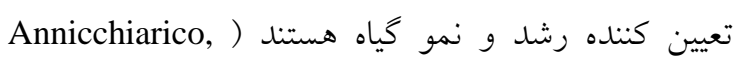

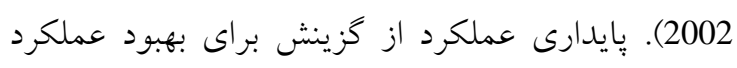

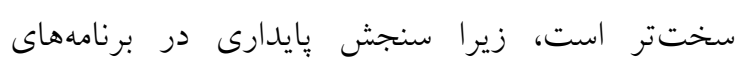

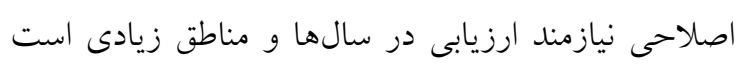


در طى زمان و مكان در محيطهاى هدف، جايى كه رقم براى كشت توصيه مىشود، صورت بخيرد. به موازات

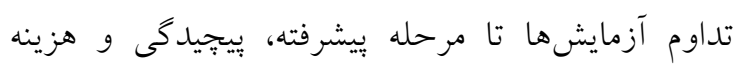


زنوتيبٍ از نظر عملكرد دانه در تمام يا بخشى از مناطق،

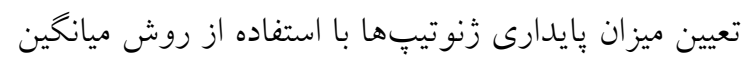

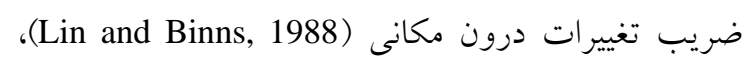

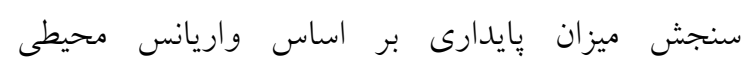

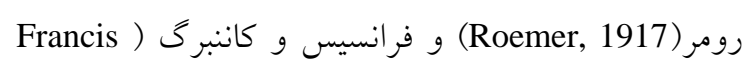



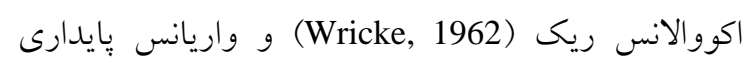

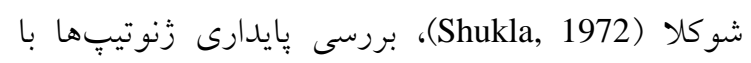

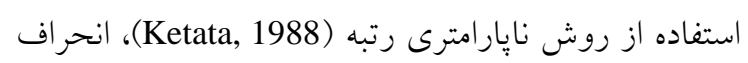

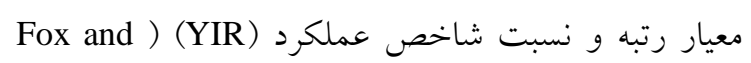
Rosielle, 1982 $S_{i}^{(3)}$ ، شامل آمارهها (Nessar and Huhn, 1987) Fox et al., ) و

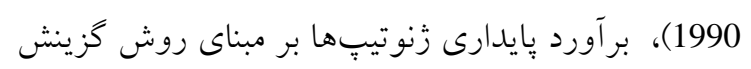

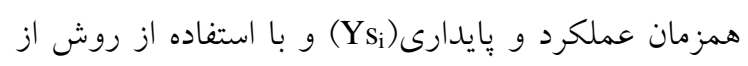

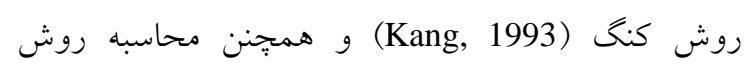

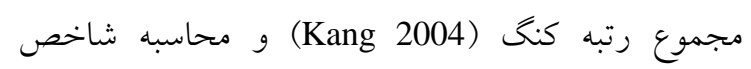

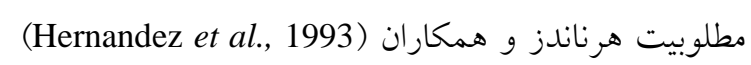
و براى انجام تجزيههاى آمارى از نرم افزار كامبيوترى هرئ SAS (2000)

\section{نتايج و بحث}

دادههاى آب و هوايى مندرج در جدول انشان آنشان داد كه در

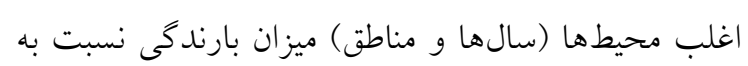

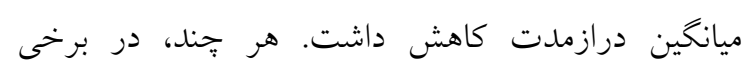

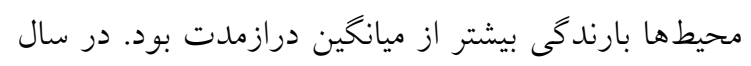

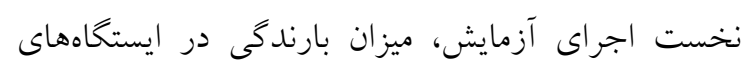

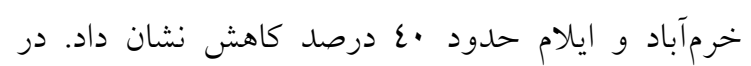

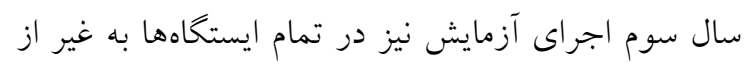

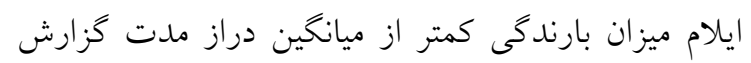

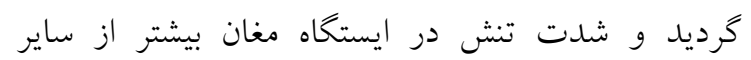

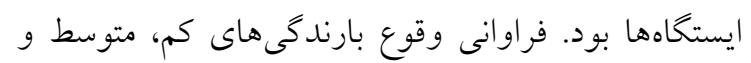

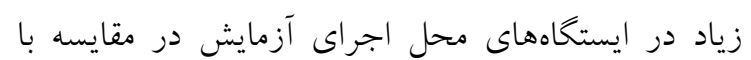

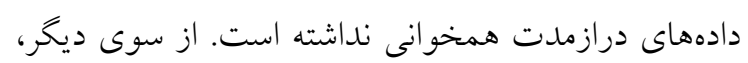

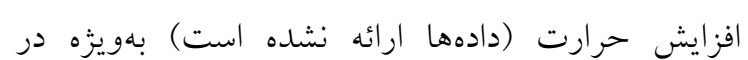

يميشرفته تر انتقال مى يابند. نتايج بررسى هاى مشابه در سال

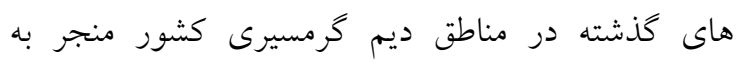

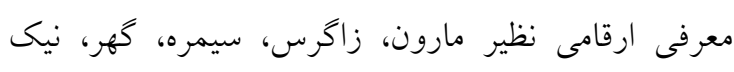

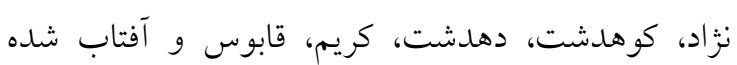

اهداف اصلى اين تحقيق عبارتند از : بررسى اثرات متقابل

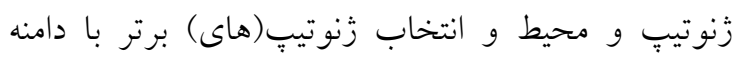

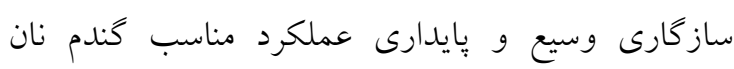
جهت كشت در مناطق ديم كرمسيرى كشور و يا ارقام داراى ساز كارى خصوصى در منطقه خاص.

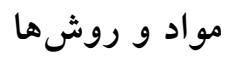

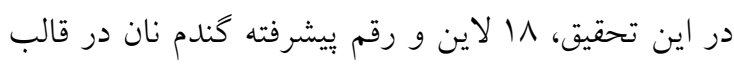
طرح بلوكهاى كامل تصادفى با جهار تكرار در ينج منطقه دئه

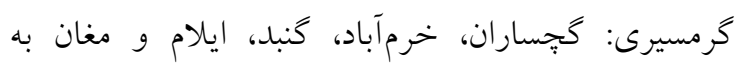

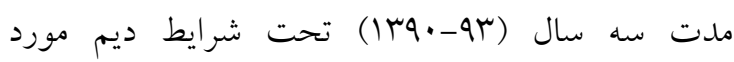

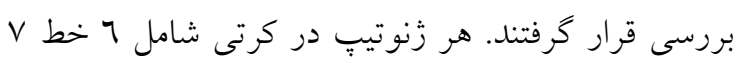

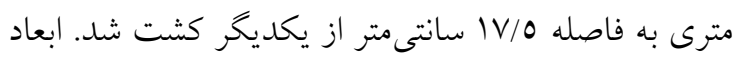

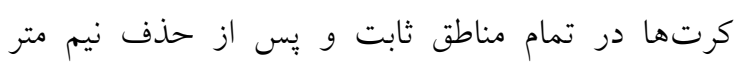
حاشيه طولى، سطح برداشت معادل س T/ مترمربع بود.



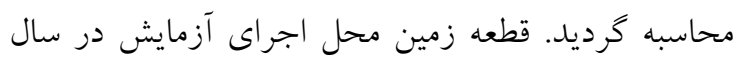

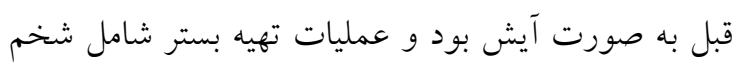

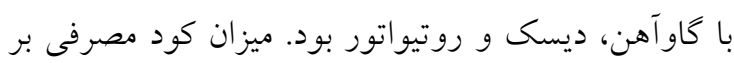

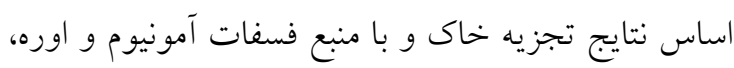
تماما قبل از كاشت با خاى مخلوط شدريه

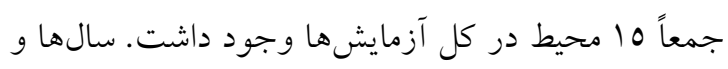

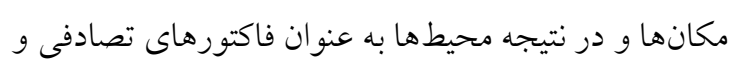
زنوتيبٍ به عنوان فاكتور ثابت در نظر كرفته شده.

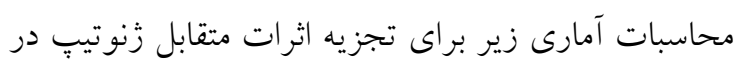

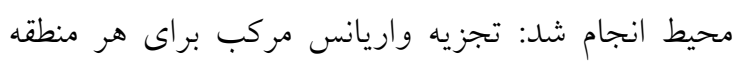

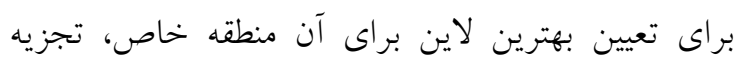

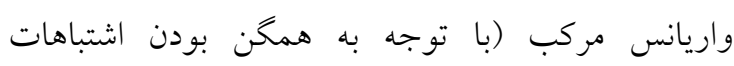

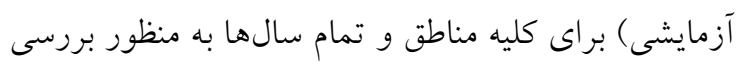

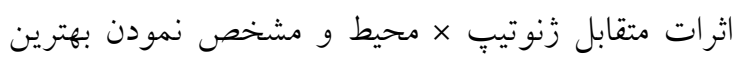


جدول ا- مقايسه ميزان بارندكى (mm) در سالهاى سو-•وبا و ميانخين درازمدت آن در ماههاى مختلف در ينج ايستخاه كجساران، گنبد، خرمآباد، مغان و ايلام

Table 1. Comparison of rainfall during 2011-2014 and long-term data in Gachsaran, Gonbad, Khoramabad,

\begin{tabular}{|c|c|c|c|c|c|c|c|c|c|c|c|}
\hline \multicolumn{12}{|c|}{ Moghan and Ilam stations } \\
\hline Location & سال & هـر & آبان & آذر & دى & بهمن & اسفند & فروردين & ارديبهشت & خرداد & جمع كل \\
\hline & Year & Mehr & Aban & Azar & Dey & Bahman & Esfand & Farvardin & Ordibehesht & Khordad & Total \\
\hline \multirow{4}{*}{ Gachsaran } & $1390-91$ & 0.0 & 92.1 & 61.1 & 42.4 & 120.7 & 47.5 & 44.8 & 0.1 & 0.0 & 408.7 \\
\hline & $1391-92$ & 0.4 & 58.7 & 211.0 & 108.9 & 38.9 & 23.6 & 13.0 & 49.2 & 0.0 & 503.7 \\
\hline & $1392-93$ & 0.0 & 117.3 & 56.2 & 161.6 & 32.3 & 24.0 & 18.0 & 1.0 & 0.0 & 410.4 \\
\hline & Longterm & 3.0 & 32.5 & 92.1 & 114.5 & 77.1 & 53.2 & 44.3 & 13.7 & 0.7 & 431.0 \\
\hline \multirow[b]{2}{*}{ كنبد } & $1390-91$ & 70.2 & 45.4 & 30.4 & 45.2 & 124.6 & 70.5 & 32.9 & 33.2 & 23.7 & 476.1 \\
\hline & $1391-92$ & 74.0 & 55.7 & 60.9 & 57.1 & 144.4 & 51.1 & 38.3 & 48.7 & 4.6 & 641.8 \\
\hline \multirow{2}{*}{ Gonbad } & $1392-93$ & 44.3 & 15.5 & 70.8 & 6.5 & 25.7 & 46.8 & 55.4 & 28.4 & 42.4 & 335.8 \\
\hline & Longterm & 40.3 & 48.5 & 40.9 & 49.2 & 40.0 & 62.9 & 51.7 & 27.5 & 16.1 & 377.1 \\
\hline \multirow{4}{*}{$\begin{array}{c}\text { خرمآباد } \\
\text { Khoramabad }\end{array}$} & $1390-91$ & 0.0 & 101.9 & 7.1 & 3.9 & 47.1 & 20.2 & 102.4 & 11.5 & 0.0 & 294.1 \\
\hline & $1391-92$ & 2.6 & 59.0 & 30.0 & 72.9 & 68.4 & 28.3 & 29.8 & 72.4 & 0.2 & 363.6 \\
\hline & $1392-93$ & 0.0 & 69.6 & 71.6 & 70.8 & 40.8 & 68.4 & 86.9 & 22.8 & 2.0 & 432.9 \\
\hline & Longterm & 10.2 & 53.4 & 77.6 & 77.6 & 83.5 & 81.3 & 78.5 & 56.8 & 5.1 & 523.9 \\
\hline \multirow{4}{*}{$\begin{array}{c}\text { مغان } \\
\text { Moghan }\end{array}$} & $1390-91$ & 59.9 & 94.5 & 2.7 & 22.2 & 28.6 & 48.4 & 19.2 & 37.8 & 34.5 & 348.8 \\
\hline & $1391-92$ & 3.4 & 41.8 & 10.1 & 25.5 & 26.5 & 18.9 & 14.4 & 14.4 & 106.1 & 261.1 \\
\hline & $1392-93$ & 23.1 & 15.7 & 47.4 & 0.4 & 5.4 & 8.2 & 22.8 & 16.9 & 17.6 & 157.5 \\
\hline & Longterm & 36.5 & 27.8 & 20.7 & 14.0 & 19.1 & 31.7 & 29.0 & 37.3 & 19.0 & 216.1 \\
\hline \multirow{4}{*}{$\begin{array}{l}\text { ايلام } \\
\text { Ilam }\end{array}$} & $1390-91$ & 0.0 & 59.6 & 5.2 & 30.5 & 77.8 & 55.0 & 93.5 & 7.7 & 0.0 & 329.3 \\
\hline & $1391-92$ & 5.1 & 61.5 & 91.8 & 68.6 & 93.2 & 14.7 & 20.4 & 40.8 & 0.0 & 396.1 \\
\hline & $1392-93$ & 0.0 & 156.4 & 100.5 & 85.4 & 95.2 & 75.9 & 31.8 & 24.8 & 4.0 & 574.0 \\
\hline & Longterm & 9.1 & 65.9 & 80.9 & 87.9 & 96.7 & 92.1 & 74.1 & 77.3 & 2.4 & 535.5 \\
\hline
\end{tabular}

درصد بتانسيل موجود كاهش مىدهد، اصلاح براى

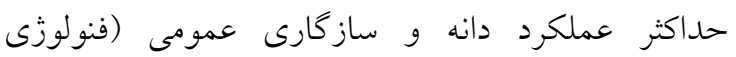
مطلوب و ساز گارى حرارتى) ممكن است براى بيشرفت مطمئن عملكرد كفايت كند. البته اين نشانه مبناى كاهش عملكردى براى تمام گياهان از قبيل دانهاى، روغنى،

حبوبات و سبزيجات وجود ندارد (Blum, 2011). تجزيه واريانس مركب سه ساله عملكرد دانه در هر يك از ينج ايستخاه نشان داد كه اثر اصلى سال در تمام مناطق و اثر متقابل زنوتيتٍ × سال نيز در تمام مناطق به استثناى

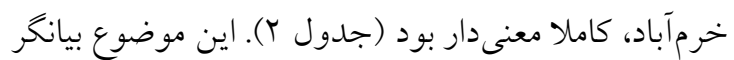
وجود اثر متقابل بين شرايط آب و هوايى مختلف بر ميانخين عملكرد زنوتيبٍ ها طى سه سال در هر يك از ايستخاهها بود. نتايج نشان داد كه اثر اصلى زنوتيبٍها معنى دار نبوده است. هر جند، بر اساس روش جند دامنهاى دانكن، تفاوت معنى دارى بين زنوتيبٍهاى آزمايشى وجود دارد (جدول ع).

در ايستخاه كجساران، تمام لاينها به استثناى لاين شماره 11 در كلاس مشترك با شاهد (رقم كريم) قرار كرفتند.
ايستخاههاى گجساران و گنبد طى مراحل حساس و بحرانى برشدن دانه كه معمولا مصادف با خشكى است، شدت كاهش محصول را افزايش داد. با در نظر كرفتن عملكرد دانه به عنوان برآيند نهايى واكنش گياه به عوامل محيطى و با زياد شدن شدت تنشهاى خشكى و كرما، ميانخين كل عملكرد دانه در مقايسه با ميانخين درازمدت

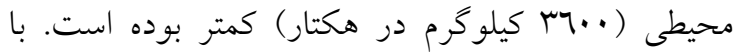
مقايسه دادهاى بارندگى و متوسط حرارت در زمان بررسى و دادههاى درازمدت، بنظر مىرسد كه بخش عمده كاهش عملكرد مربوط به كاهش بارندگى و سبس افزايش حرارت باشد، زيرا اصولا تنش كرما عاملى است كه هرجنا، بيشترين سطح زير كشت را تحت تاثير قرار مىدهل، ولى تنش خشكى بيشترين خسارت اقتصادى را به همراه دارد (Kosina et al., 2007). اثر منفى تنش خشكى در تظاهر عملكرد دانه در كشورهاى توسعه يافته و درحال توسعه دنيا به خوبى مستند شده است

.(Hernandez, 2004; Guo, 2004; Passioura, 2007) براى گૂاهان دانهاى شواهد كافى موجود است كه نشان

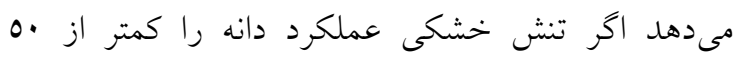


ئزوهش هاى زنتيك گياهى / جلد ع / شماره Y /

جدول r- تجزيه واريانس مركب سه ساله عملكرد دانه زنوتيبٍهاى كندم نان در هر يك از مناطق در سه سال زراعى

Table 2. Combined analysis of variance on grain yield for wheat genotypes in each station during 3 years

\begin{tabular}{|c|c|c|c|c|c|c|}
\hline \multirow{2}{*}{$\begin{array}{c}\text { منابع تغييرات } \\
\text { Source of } \\
\text { variation }\end{array}$} & \multirow{2}{*}{$\begin{array}{l}\text { درجه آزادى } \\
\text { Degree of } \\
\text { freedom }\end{array}$} & \multicolumn{5}{|c|}{$\begin{array}{l}\text { ميانخين مربعات } \\
\text { Mean of square }\end{array}$} \\
\hline & & 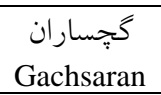 & $\begin{array}{c}\text { كنبد } \\
\text { Gonbad }\end{array}$ & $\begin{array}{c}\text { خرمرآباد } \\
\text { Khoramabad }\end{array}$ & $\begin{array}{c}\text { مغان } \\
\text { Moghan }\end{array}$ & $\begin{array}{l}\text { ايلام } \\
\text { Ilam }\end{array}$ \\
\hline $\begin{array}{l}\text { سال } \\
\text { Year }\end{array}$ & 2 & $17678660^{* *}$ & $55590376^{* *}$ & $104794289^{* *}$ & $153417232^{* *}$ & $18538401^{* *}$ \\
\hline $\begin{array}{c}\text { خطاى سال } \\
\text { Error (Year) }\end{array}$ & 9 & 1943397 & 513756 & 269647 & 428687.2 & 1498610.9 \\
\hline Genotype زنوتيب & 17 & $452895.1^{\mathrm{ns}}$ & $469044^{\mathrm{ns}}$ & $219476^{\mathrm{ns}}$ & $235628.9^{\mathrm{ns}}$ & $581371^{\mathrm{ns}}$ \\
\hline 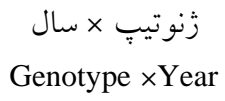 & 34 & $453195.5^{* *}$ & $412454^{* *}$ & $425290^{\mathrm{ns}}$ & $253185.3^{* *}$ & $336572^{*}$ \\
\hline $\begin{array}{c}\text { خطاى كل } \\
\text { Total error }\end{array}$ & 153 & 181400.8 & 28366 & 458326 & 87785 & 213345 \\
\hline
\end{tabular}

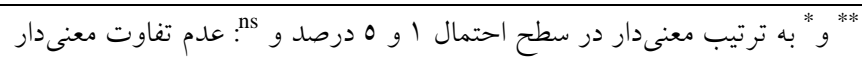

* and ${ }^{* *}$ means significant at 5 and 1 percent probability level, respectively, and ${ }^{\text {ns. non-significant }}$

معنى دار شدن اثر متقابل سهجانبه (زنوتيب × محيط) نشان داد كه روند واكنش زنوتيبٍها در محيطهاى مختلف يكسان نبوده است (تغيير در ترتيب). بنابراين، براى يافتن لاين هاى مناسب براى مناطق ديم گرمسيرى، تنها اتكا به ميانخين لاينها كافى نمىباشد و مىبايست با استفاده از

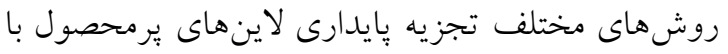
عملكرد يايدار را گزينش نمود. روشهاى تجزيه پايدارى يارامترى تكمتغيره

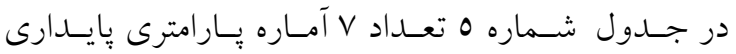

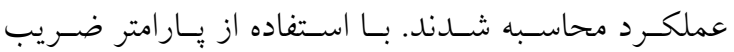

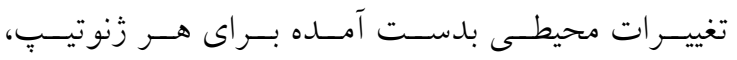
زنوتيبٍهاى داراى كمترين مقادير ضريب تغييرات (شماره IV و 1 كه ميانخين عملكردى بالاتر از ميـانخين عملكـرد

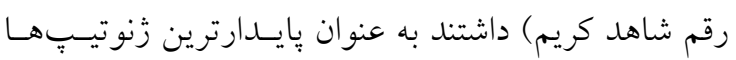
Plaisted and ) انتخاب شدند. در روش پِاستد و يترسون

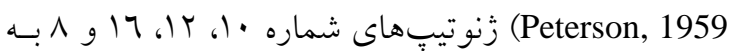
علت داشتن مقادير كم $\theta_{i}$ به عنـوان واريتـهـهـاى پايسـار معرفى شدند. بدين معنى كه سهم كمتـرى در اثـر متقابـل

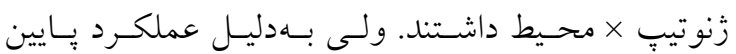

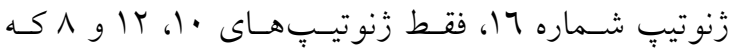
داراى عملكردى بـالاتر از ميـانكين عملكـــد كـل و رقـم
همين لاين شماره 11 و لاينهاى شماره V، 10 و 17 در ايستخاه گنبد نسبت به شاهد در سطح احتمال 0 \% كاهش داشتند. در ايستخاههاى خرمآباد و ايلام تمام لاينها به اتفاق شاهد در كلاس واحدى قرار داشتند. معهذا، لاينهاى شماره r و 0 در ايستخاه مغان در مقايسه با رقم كريم كاهش معنى دار نشان دادند (جدول ع). نتايج بدست آمده از تجزيه واريانس مركب بر روى عملكرد دانه، اثرات متقابل سال× مكان و زنوتيب × سال × مكان را معنى دار نشان داد ولى اثر اصلى زنوتيقٍ، سال و مكان معنىدار نبود (جدول س). تنوع آب و هوايى بين مكانهاى مختلف در هر سال و وقوع خشكسالى با شدت هاى متفاوت در سالهاى مختلف براى هر مكان، مانع از معنى دار شدن اثرات اصلى سال و مكان و اثرات متقابل زَنوتيٌ× مكان و زَنوتيب × سال بوده است.

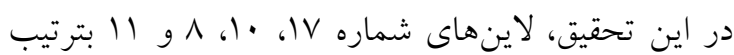

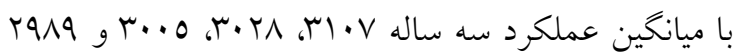
كيلو گرم در هكتار بيشترين ميزان توليد دانه را داشتند. هر

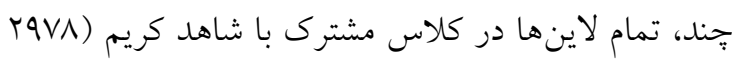
كيلو گرم در هكتار) قرار گرفتند، ولى لاينهاى شماره r و V با توليدكمترين محصول دانه نسبت به رقم كريم كاهش معنى دارى در سطح احتمال 0\% نشان دادند (جدول ع). 
مورد آزمايش نوسان كمترى داشته باشد و به همين دليـل

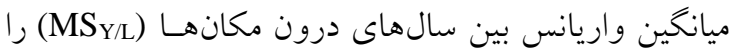
به عنوان يارامتر يايدارى ييشنهاد دادند. با استفاده از ايـن

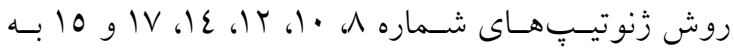

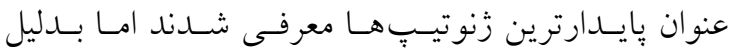

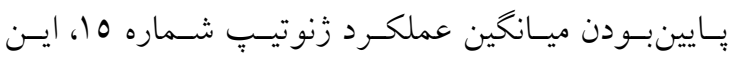



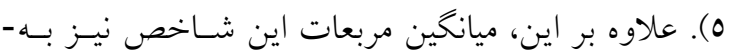

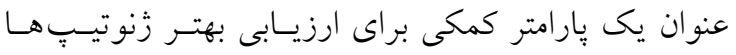

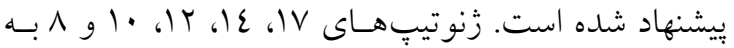
ترتيب داراى كمتـرين ميـزان ميـانخين مربعـات (MSPI) بودند. بنابراين، به عنوان زنوتيِهاى بِيدار در ايسن روش

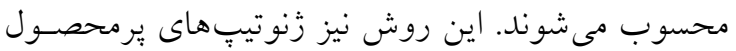

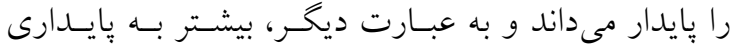

ديناميك يا زراعى گرايش دارد (Flores et al., 1998).
شاهد كريم بودند بهعنوان بِيدارترين زنوتيـيـهـا در ايسن

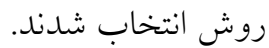
در روش يلاستد (Plaisted, 1960) به علت بـزرگ بـودن

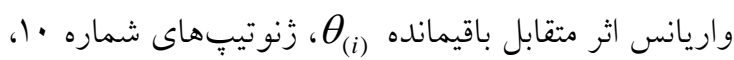

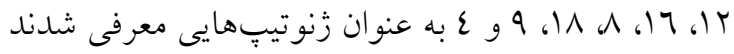

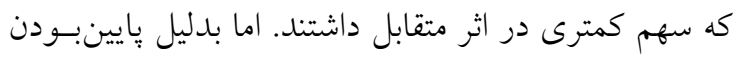

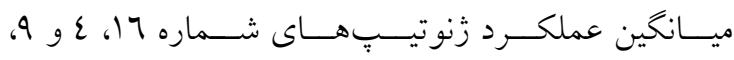

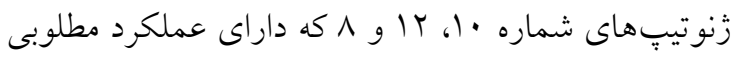
بودند بهعنوان پِايدارترين زنوتيِّها در اين روش انتخاب شدند. در روشهاى اكووالانس ريـى (Wrick, 1962) و واريــانس شـو كلا (Shukla, 1972) نتـــيج نشــان داد

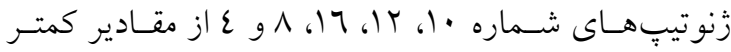
اكووالانس و واريانس اثر متقابل برخوردار بودند. شاخص (Lin and Binns, 1988) كه توسط لين و بينز (PI) برتئ معرفى شد واريتهاى را بايدار مى ماند كه در طول سالهاى

جدول ب- نتايج تجزيه واريانس مركب بر روى عملكرد دانه زنوتيبهاى كندم در تمام مناطق و سالهاى مختلف 3 مالف

Table 3. Combined analysis of variance on grain yield for wheat genotypes in each station during 3 years

\begin{tabular}{|c|c|c|c|c|}
\hline $\begin{array}{c}\text { منابع تغييرات } \\
\text { Source of variation }\end{array}$ & $\begin{array}{l}\text { درجه آزادى } \\
\text { Degree of } \\
\text { freedom }\end{array}$ & $\begin{array}{c}\text { جمع مجذورات } \\
\text { Source of square }\end{array}$ & $\begin{array}{l}\text { ميانكين مجذورات } \\
\text { Mean of square }\end{array}$ & $\begin{array}{l}\text { F نسبت } \\
\text { F ratio }\end{array}$ \\
\hline $\begin{array}{c}\text { مكان } \\
\text { Location }\end{array}$ & 4 & 1115207884 & 278801971 & $3.36^{\mathrm{ns}}$ \\
\hline $\begin{array}{l}\text { سال } \\
\text { Year }\end{array}$ & 2 & 37472908 & 18736454 & $0.23^{\text {ns }}$ \\
\hline $\begin{array}{c}\text { سال × مكان } \\
\text { Year × Location }\end{array}$ & 8 & 662565007 & 82820626 & $88.97^{* *}$ \\
\hline $\begin{array}{l}\text { خطاى اول } \\
\text { Error (1) }\end{array}$ & 45 & 41886879 & 930820 & \\
\hline $\begin{array}{c}\text { زنوتيب } \\
\text { Genotype }\end{array}$ & 17 & 7975011 & 469118 & $1.09^{\text {ns }}$ \\
\hline $\begin{array}{c}\text { زنوتيب × سال } \text { × } 1 \text { Year } \\
\text { Genotype }\end{array}$ & 34 & 13493017 & 396853 & $1.06^{\mathrm{ns}}$ \\
\hline $\begin{array}{c}\text { زنوتيب × مكان } \text { × Location } \\
\text { Genotype }\end{array}$ & 68 & 25318040 & 372324 & $1.00^{\text {ns }}$ \\
\hline 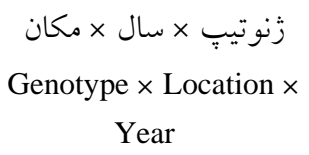 & 136 & 50450681 & 370961 & $1.91^{* *}$ \\
\hline $\begin{array}{l}\text { خطاى دوم } \\
\text { Error (2) }\end{array}$ & 765 & 148291114 & 193845 & \\
\hline
\end{tabular}

* and ${ }^{* *}$ means significant at 5 and 1 percent probability level, respectively, and ns: non-significant 
جدول ع- متوسط سه ساله عملكرد دانه زنوتيب: هاى گندم نان در هر يك از مناطق

Table 4. Three years mean yield for wheat genotypes in each station

\begin{tabular}{|c|c|c|c|c|c|c|c|}
\hline Ent & 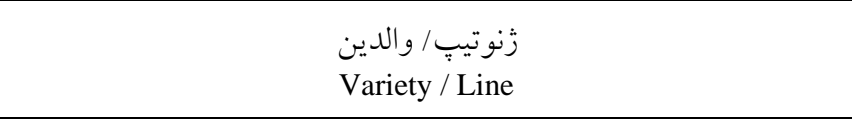 & $\begin{array}{c}\text { Sجm } \\
\text { Gachsara } \\
\text { n }\end{array}$ & $\begin{array}{c}\text { Sonbad } \\
\end{array}$ & $\begin{array}{l}\text { خرم آباد } \\
\text { Khora } \\
\text { mabad }\end{array}$ & $\begin{array}{c}\text { Mogha } \\
\text { n }\end{array}$ & $\begin{array}{l}\text { ايلام } \\
\text { Ilam }\end{array}$ & $\begin{array}{l}\text { تمام مناطق } \\
\text { All } \\
\text { locations }\end{array}$ \\
\hline 1 & KARIM & 3782 & 3938 & 3961 & 1678 & 1530 & 2978 \\
\hline 2 & $\begin{array}{c}\text { KAL/BB//YD/3/PASTOR CMSS99M00981S-0P0M-040SY- } \\
\text { 040M-040SY-16M-0ZTY-0M-0SY }\end{array}$ & 3631 & 4032 & 3488 & 1473 & 1242 & 2773 \\
\hline 3 & $\begin{array}{l}\text { CROC_1/AE.SQUARROSA (224)//OPATA/3/ PASTOR } \\
\text { CMSA00Y00086S-0P0Y-040M-040SY-030M-18ZTY-0M-0SY }\end{array}$ & 3246 & 4137 & 3579 & 1671 & 1607 & 2848 \\
\hline 4 & $\begin{array}{c}\text { CHEN/AE.SQ//2*WEAVER/3/BABAX/4/JARUCMSS99Y03525 } \\
\text { T-040M-040Y-040M-040SY-040M-19Y-010M-0ZTB-0SY- }\end{array}$ & 3406 & 4029 & 3760 & 1778 & 1500 & 2894 \\
\hline 5 & $\begin{array}{l}\text { TAM200/TUI//MILAN/KAUZ/3/CROC-1/AE. SQUARROSA } \\
\text { (224)// OPATACMSS97M03159T-040Y-0B-0AP-2AP-0APS- }\end{array}$ & 3633 & 4023 & 3570 & 1448 & 1958 & 2927 \\
\hline 6 & $\begin{array}{l}\text { PRL/2*PASTORCGSS97Y00034M-099TOPB-027Y-099M- } \\
\text { 099Y-099M-27Y-0B }\end{array}$ & 3668 & 3914 & 3796 & 1917 & 1213 & 2901 \\
\hline 7 & $\begin{array}{c}\text { CNDO/R143//ENTE/MEXI_2/3/AEGILOPS QUA RR OSA } \\
\text { (TAUS)/4/WEAVER/5/PASTOR CMSS96 M03 230S-050M- } \\
\text { 050SY-040SY-030M-19SY-010M-0Y-0SY }\end{array}$ & 3507 & 3354 & 3516 & 1845 & 1679 & 2780 \\
\hline 8 & $\begin{array}{c}\text { WHEAR/KUKUNA/3/C80.1/3*BATAVIA//2*WBLL1CGSS03B } \\
\text { 00080T-099Y-099M-099Y-099M-7WGY-0B }\end{array}$ & 3708 & 4003 & 3590 & 1968 & 1756 & 3005 \\
\hline 9 & $\begin{array}{l}\text { BABAX/LR42//BABAX/3/ER2000CMSA01Y00176S-040P0Y- } \\
\text { 040M-030ZTM-040SY-30M-0Y-0SY }\end{array}$ & 3697 & 4089 & 3726 & 1757 & 1431 & 2940 \\
\hline 10 & $\begin{array}{l}\text { KS82142/2*WBLL1CMSA01Y00397T-040M-040P0Y-040M- } \\
\text { 030ZTM-040SY-4M-0Y-0SY }\end{array}$ & 3931 & 4038 & 3792 & 1858 & 1521 & 3028 \\
\hline 11 & $\begin{array}{l}\text { KS82142/2*WBLL1CMSA01Y00397T-040M-040P0Y-040M- } \\
\text { 0307TM-040SY-21M-0Y-0SY }\end{array}$ & 4007 & 3969 & 3596 & 1862 & 1513 & 2989 \\
\hline 12 & $\begin{array}{l}\text { BERKUT/3/ATTILA*2//CHIL/BUCCMSA01M00078S-040P0M- } \\
\text { 030ZTM-040SY-040M-43Y-0M-0SY }\end{array}$ & 3739 & 3925 & 3776 & 1757 & 1633 & 2966 \\
\hline 13 & $\begin{array}{l}\text { PASTOR//HXL7573/2*BAU/3/WBLL1PTSS02Y00023S-0Y- } \\
\text { 030ZTM-040SY-040M-19Y-0M-0SY }\end{array}$ & 3733 & 4138 & 3516 & 1829 & 1533 & 2950 \\
\hline 14 & $\begin{array}{l}\text { MEX94.27.1.20/3/SOKOLL//ATTILA/3*BCNPTSS02B00132T- } \\
\text { OTOPY-OB-0Y-0B-38Y-0M-OSY }\end{array}$ & 3513 & 4071 & 3628 & 1816 & 1852 & 2976 \\
\hline 15 & $\begin{array}{l}\text { WHEAR/KIRITATI/3/C80.1/3*BATAVIA//2*WBLL1CGSS03B } \\
\text { 00077T-099Y-099M-099Y-099M-47WGY-0B }\end{array}$ & 3776 & 3630 & 3765 & 1792 & 1828 & 2958 \\
\hline 16 & $\begin{array}{c}\text { TC870344/GUI//TEMPORALERA M 87/AGR/3/2* } \\
\text { WBLL1CMSA01Y00725T-040M-040P0Y-040M-030ZTM- } \\
\text { TC870344/GUI/TEMPORALERA M 87/AGR/3/2* WBLL1 }\end{array}$ & 3727 & 3740 & 3497 & 1740 & 1524 & 2846 \\
\hline 17 & $\begin{array}{l}\text { TC870344/GUI//TEMPORALERA M 87/AGR/3/2* WBLL1 } \\
\text { CMSA 01Y00725T-040M-040P0Y-040M-030ZTM-040SY-33M- } \\
\text { CHRZ//BOW/CROW/3/WBLL1/4/CROC_1/AE.SQUARROSA }\end{array}$ & 3966 & 3879 & 3688 & 1953 & 2050 & 3107 \\
\hline 18 & $\begin{array}{l}\text { (213)//PGOCMSA02Y00509T-040M-040P0Y-040ZTM-040SY- } \\
\text { 040M-15ZTY-03M-0Y }\end{array}$ & 3493 & 3771 & 3508 & 1747 & 1563 & 2816 \\
\hline
\end{tabular}

جدول 0- مقادير آمارههاى يارامترى يايدارى عملكرد دانه زنوتيبٍ هاى كندم نان در سه سال اجراى يزوهش

Table 5. Stability parametric statistics for grain yield of wheat genotypes during 3 years

\begin{tabular}{|c|c|c|c|c|c|c|c|c|}
\hline PI & $D_{i}^{2}$ & $\theta_{(i)}$ & $\theta_{i}$ & $\sigma_{i}^{2}$ & $W_{i}^{2}$ & $\mathrm{CVi}$ & $\begin{array}{l}\text { ميانخين } \\
\text { Mean }\end{array}$ & زَنوتيٍّ \\
\hline 209487 & 3376771 & 85174 & 162432 & 239690 & 3055734 & 48.3 & 2978 & G1 \\
\hline 294193 & 2333102 & 91626 & 110816 & 130005 & 1690763 & 53.6 & 2773 & G2 \\
\hline 243155 & 1622856 & 93286 & 97540 & 101793 & 1339685 & 48.7 & 2848 & G3 \\
\hline 202208 & 1121693 & 95906 & 76577 & 57248 & 785340 & 47.9 & 2894 & G4 \\
\hline 223962 & 2055800 & 88733 & 133963 & 179192 & 2302871 & 43.3 & 2927 & G5 \\
\hline 239820 & 2402772 & 91673 & 110441 & 129208 & 1680846 & 51.9 & 2901 & G6 \\
\hline 282336 & 1510268 & 91355 & 112985 & 134616 & 1748139 & 45.2 & 2780 & G7 \\
\hline 140661 & 890169 & 96260 & 73743 & 51226 & 710400 & 44.7 & 3005 & G8 \\
\hline 199498 & 1331946 & 95422 & 80453 & 65485 & 887842 & 48.2 & 2940 & G9 \\
\hline 126844 & 1058458 & 97505 & 63785 & 30066 & 447074 & 47.8 & 3028 & G10 \\
\hline 153566 & 1505613 & 94471 & 88060 & 81649 & 1088994 & 47.3 & 2989 & G11 \\
\hline 141899 & 925442 & 97258 & 65763 & 34268 & 499365 & 47.3 & 2966 & G12 \\
\hline 187933 & 1409151 & 94435 & 88342 & 82249 & 1096471 & 47.1 & 2950 & G13 \\
\hline 146913 & 1601029 & 93841 & 93098 & 92356 & 1222239 & 47.3 & 2976 & G14 \\
\hline 157729 & 970800 & 94567 & 87287 & 80006 & 1068559 & 43.1 & 2958 & G15 \\
\hline 216833 & 657545 & 97034 & 67550 & 38065 & 546624 & 46.4 & 2846 & G16 \\
\hline 95733 & 1120398 & 94052 & 91406 & 88759 & 1177478 & 41.5 & 3107 & G17 \\
\hline 259207 & 867949 & 95052 & 83411 & 71770 & 966065 & 45.2 & 2816 & G18 \\
\hline
\end{tabular}


زنوتيِّها در اين روش معرفى شدند. البته به دليل ميـزان

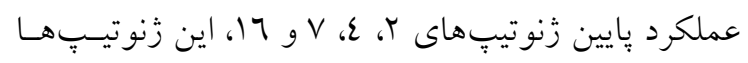

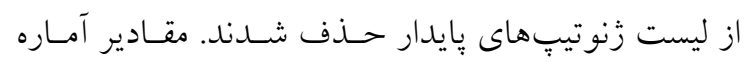
S $S_{i}^{(6)}$

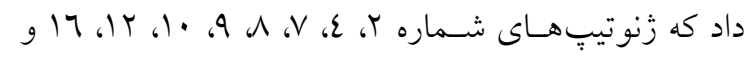

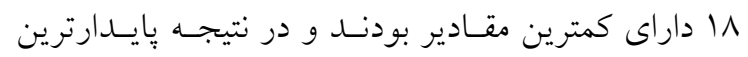

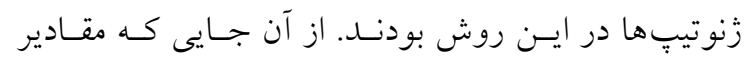

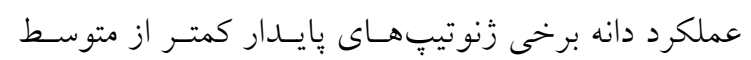

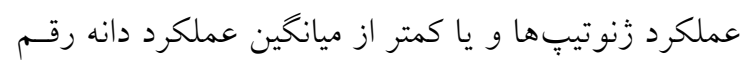

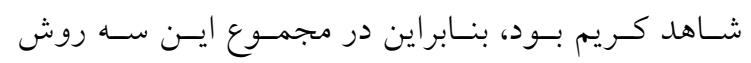

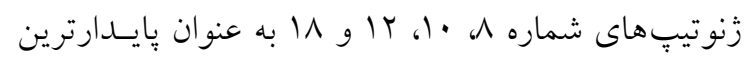

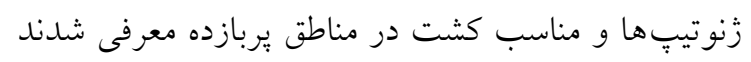

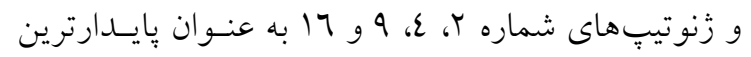

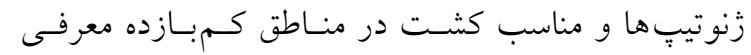
شدند. زنوتيبٍ هاى داراى كمتـرين مقــادير

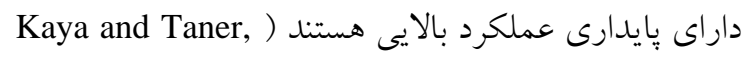
2003; Kilic et al., 2010 بدست آمده از عملكرد تصحيح شده و تصحيح نشــده بـا

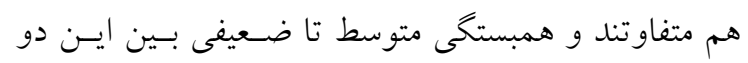

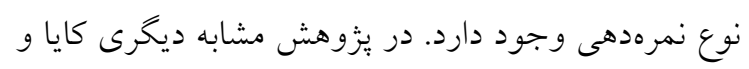

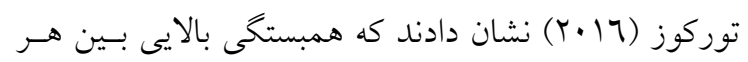
جهـار شـاخص نإِـارامترى

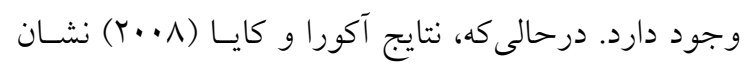
داد كــه بـين نتــايج همبستخى وجود ندارد و بيش ترين همبستخى بـين

$$
\text { و }
$$

شاخص نايارامترى فو كس و همكاران (Fox et al., 1990)

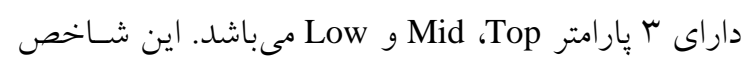

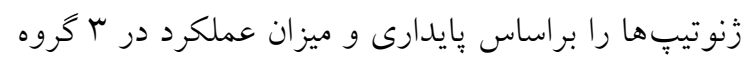

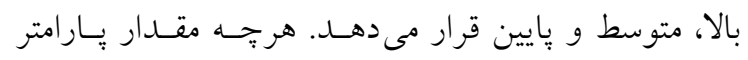

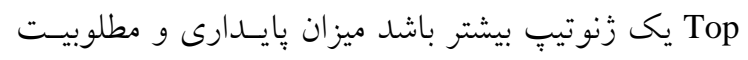

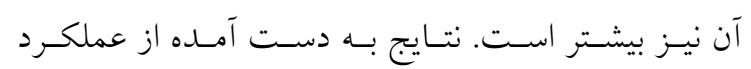

Hernandez ( هاخص مطلوبيت (DI) هرناندز و همكاران (et al., 1993

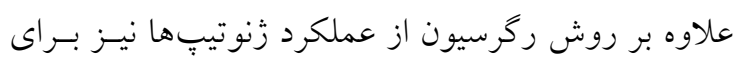

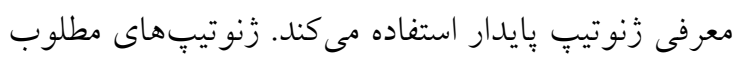

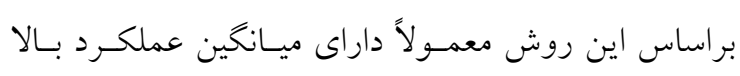
مى باشند. هر جه شاخص مطلوبيت مقدار بيش ترى داشسته دئه باشد، نشان دهندهى بايدارى بالاتر است. براساس مقــادير

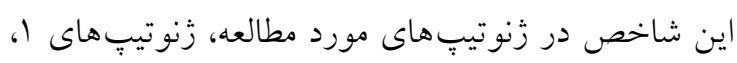

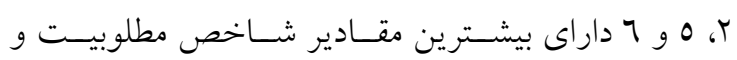

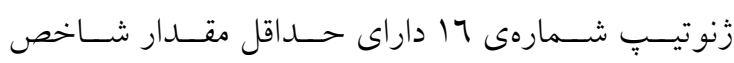

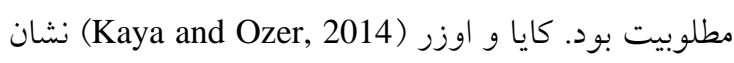

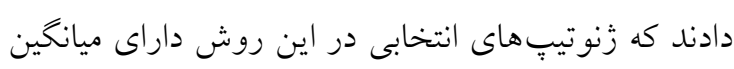

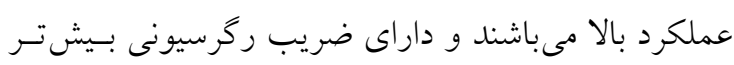

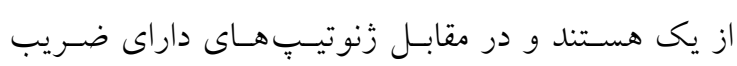
ركرسيونى كمتر از يكى در اين روش نايايدار بودند. نتايج

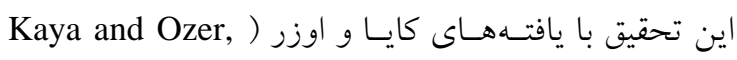
2014) و محمـــى و همكــاران ( Mohammadi et al.,

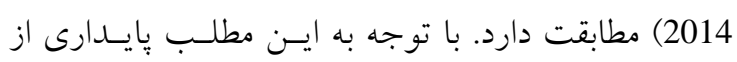

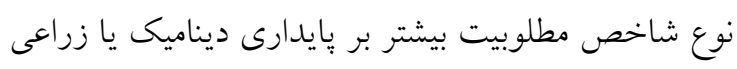

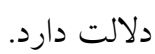
روشهاى نإيارامترى پپايدارى عملكرد دانه

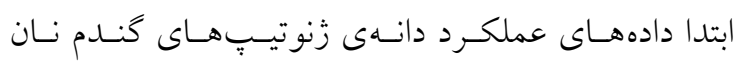

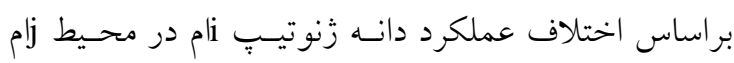
با ميانخين عملكرد زنـوتييى (X)

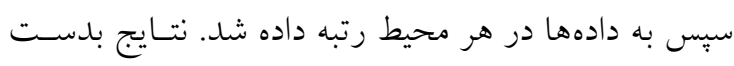

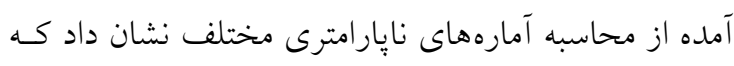

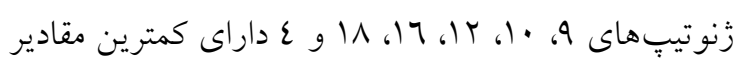

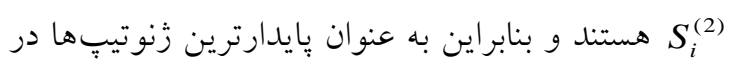

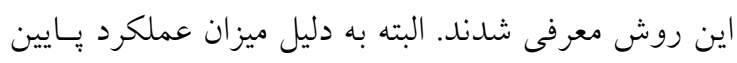



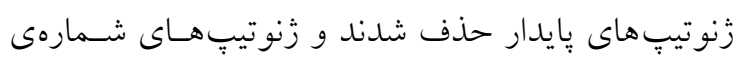

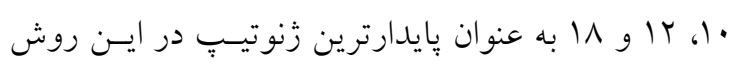

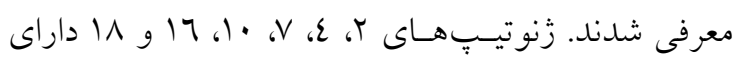
كمتــرين مقــادير 
نتايج بدسـت آمــه از روش مجمسوع رتبـه كنـع نشـان

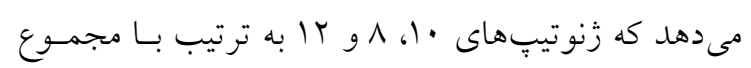

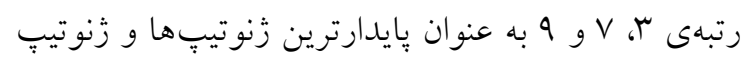

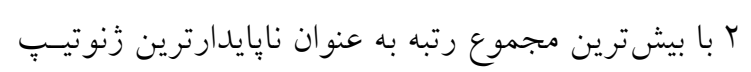

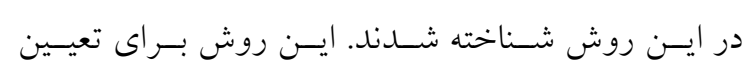
بايدارى محصولات مختلف در بُزوهش هاى زيادى به كار Kilic et al., ،Akcura and Kaya, 2008 (فتسه است 2001; Zali et al., 2011, Mortazavian and Azizinia, .(2014; Zarei Soltankohi and Farshadfar, 2016 در حالنى كه ميزان عملكرد دانه زنوتيبٍهاى مورد بررسى تفاوت زيادى نشان نمىدهد، استفاده از ساير صفات مهم موثر در توليد تحت تنشهاى خشكى و گرما در انتخاب

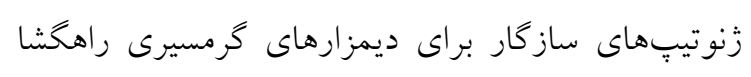

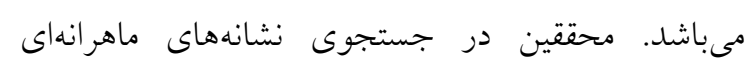

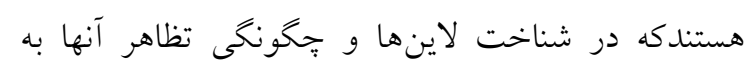
خصوص در زمانى كه تفاوت بين بهترين لاينها كوجى

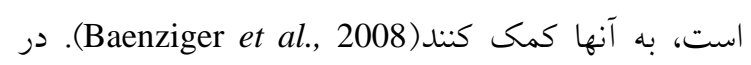
اين بررسى نيز علاوه بر عملكرد دانه بالاى بايدار در

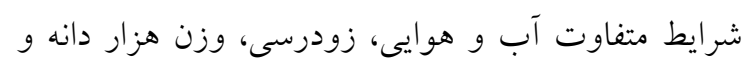
ارتفاع بوته مناسب از خصوصيات برجسته لاينهاى

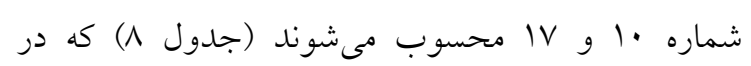
ساز كارى گياه با محيط هدف و يذّيرش كشاورزان بسيار تاثير گذار هستند. لاين بر محصول شماره • إبا بايدارى بالا ، زودرسى، ارتفاع بوته و وزن هزار دانه مناسب از بـان

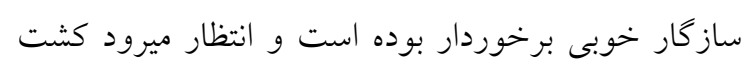
آن تحت نوسانات آب و هو ايى اقليم ديم گرمسيرى توليد مطلوبى به همراه داشته باشد. علاوه بر اين، لاين شماره



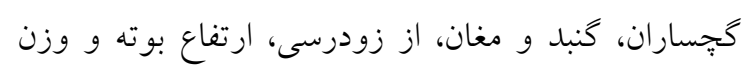
هزار دانه مطلوبى برخوردار است.
زنوتيبٍ هاى گندم نان در 10 محيط اين بُزوهش نشان داد

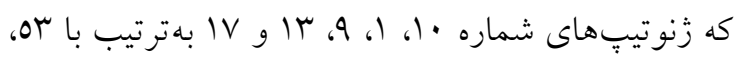

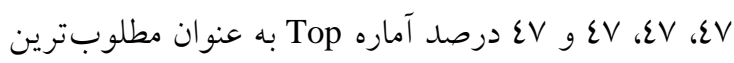

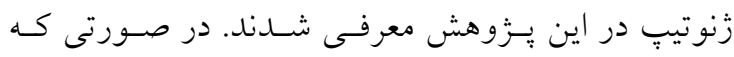

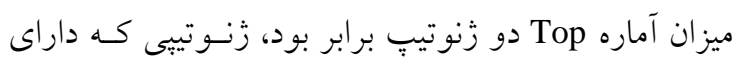

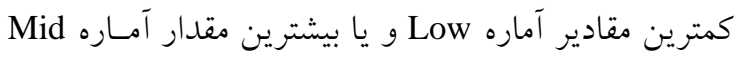

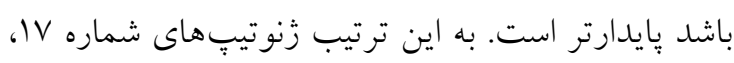

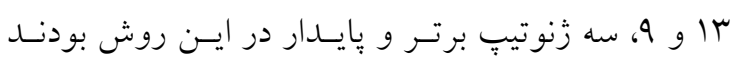

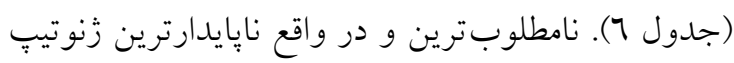

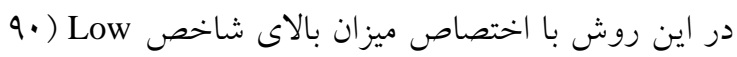

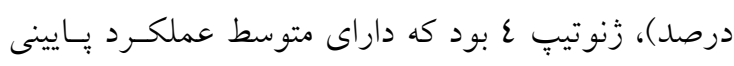

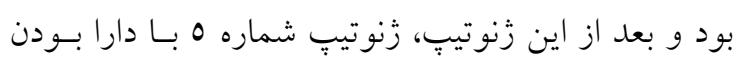

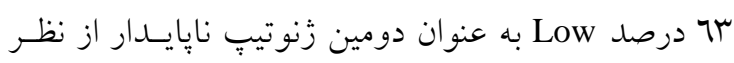

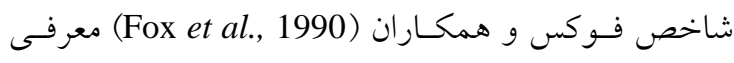
شدند. فرشـادفر و همكـاران (Farshadfar et al., 2012)،

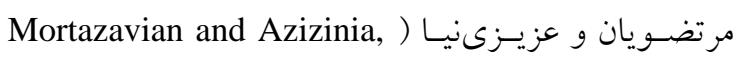

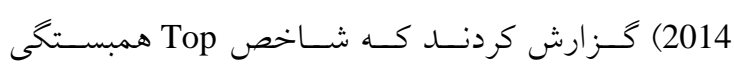
معنى دارى فقط با ميانخين عملكـــد دانـه و ميـانخين رتبـهـ

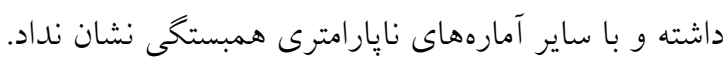

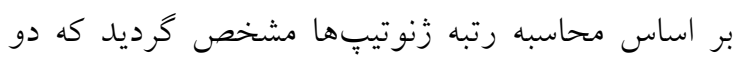

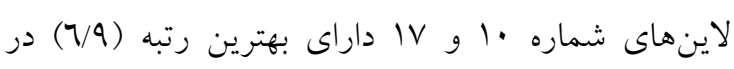
مناطق و سالهاى مختلف بودند. علاوه بر اين، تعيين ميزان يايدارى با استفاده از روش انحراف معيار رتبه زنوتيبها نشان داد كه حداقل انحراف معيار رتبه بترتيب

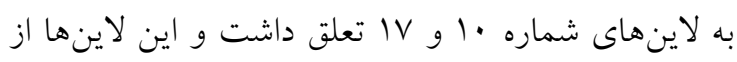

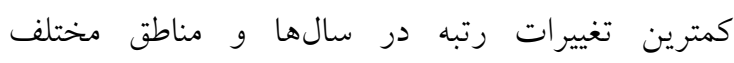
برخوردار بودند. نتايج مشابهى توسط محمدى و همكاران براى جو و كندم (Mohammadi et al., 2012, 2013)

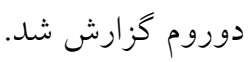

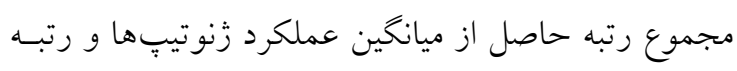

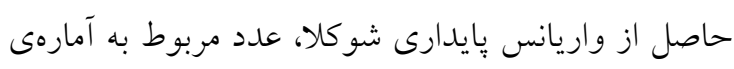
مجموع رتبهى كنـ (Kang, 2004) را فـراهم مسى كنـد. 


$$
\text { جدول 7- مقادير آمارههاى نايارامترى بِايدارى عملكرد دانه زنوتيبٍهاى گندم نان }
$$

Table 6. Stability non-parametric statistics of for grain yield of wheat genotypes during 3 years

\begin{tabular}{cccccccccc}
\hline R-Sum & Low & Mid & Top & $S_{i}^{(6)}$ & $S_{i}^{(3)}$ & $S_{i}^{(2)}$ & $\begin{array}{c}\text { Mini } \\
\text { Mean }\end{array}$ & Genotype \\
\hline 23 & 47 & 7 & 47 & 11.45 & 82.55 & 53.12 & 2978 & G1 \\
33 & 67 & 13 & 20 & 5.41 & 31.84 & 31.40 & 2773 & G2 \\
27 & 40 & 33 & 27 & 6.58 & 39.77 & 35.40 & 2848 & G3 \\
18 & 33 & 47 & 20 & 5.51 & 29.58 & 22.69 & 2894 & G4 \\
28 & 20 & 47 & 33 & 7.06 & 44.66 & 32.21 & 2927 & G5 \\
26 & 40 & 27 & 33 & 8.06 & 50.19 & 34.10 & 2901 & G6 \\
33 & 40 & 40 & 20 & 5.68 & 30.84 & 32.92 & 2780 & G7 \\
7 & 27 & 40 & 33 & 6.65 & 36.21 & 25.57 & 3005 & G8 \\
16 & 27 & 27 & 47 & 7.45 & 38.35 & 21.70 & 2940 & G9 \\
3 & 7 & 40 & 53 & 6.77 & 32.44 & 17.84 & 3028 & G10 \\
13 & 40 & 20 & 40 & 8.90 & 58.27 & 33.52 & 2989 & G11 \\
9 & 33 & 40 & 27 & 5.49 & 25.92 & 16.38 & 2966 & G12 \\
19 & 27 & 27 & 47 & 7.21 & 41.44 & 28.69 & 2950 & G13 \\
18 & 27 & 33 & 40 & 7.44 & 43.80 & 26.70 & 2976 & G14 \\
16 & 33 & 33 & 33 & 7.09 & 41.76 & 27.00 & 2958 & G15 \\
18 & 33 & 53 & 13 & 4.50 & 26.45 & 18.74 & 2846 & G16 \\
12 & 13 & 40 & 47 & 7.62 & 33.78 & 34.55 & 3107 & G17 \\
23 & 53 & 27 & 20 & 5.67 & 31.71 & 21.84 & 2816 & G18 \\
\hline
\end{tabular}

جدول V- متوسط سه ساله رتبه و انحراف معيار رتبه براى زنوتيٍِهاى گندم نان تحت بررسى

Table 7. Three years rank average and its standard deviation for wheat genotypes during 3 years

\begin{tabular}{|c|c|c|c|c|c|c|c|c|c|c|c|c|}
\hline & & ر رتبه & حراف معيا & & & & & & متوسط ر & & & \\
\hline & & Rank Star & idard devi & iation & & & & Ran & average & & & \\
\hline ميانخين & ايلام & مغان & خرمآباد & كنبد & گ گجساران & ميانخين & ايلام & مغان & خرمآباد & كنبد & كُجساران & Genotype \\
\hline Average & Ilam & Moghan & $\begin{array}{c}\text { Khoram } \\
\text { abad }\end{array}$ & Gonbad & Gachsaran & Average & Ilam & Moghan & $\begin{array}{c}\text { Khoram } \\
\text { abad }\end{array}$ & Gonbad & Gachsaran & \\
\hline 7.20 & 8.72 & 8.66 & 9.24 & 8.08 & 5.86 & 8.8 & 11.0 & 11.0 & 6.3 & 8.3 & 7.3 & 1 \\
\hline 5.27 & 7.00 & 4.93 & 6.43 & 6.93 & 3.46 & 12.2 & 13.0 & 14.7 & 12.3 & 10.0 & 11.0 & 2 \\
\hline 5.44 & 4.62 & 6.51 & 5.20 & 2.89 & 4.62 & 10.4 & 10.3 & 10.7 & 11.0 & 4.7 & 15.3 & 3 \\
\hline 4.63 & 3.06 & 4.00 & 5.57 & 5.13 & 2.52 & 10.1 & 10.7 & 11.0 & 8.0 & 6.3 & 14.7 & 4 \\
\hline 5.34 & 3.79 & 5.13 & 4.51 & 3.61 & 8.00 & 8.9 & 3.7 & 12.3 & 9.7 & 9.0 & 10.0 & 5 \\
\hline 5.80 & 3.79 & 5.69 & 4.00 & 6.51 & 7.23 & 9.4 & 15.3 & 6.7 & 7.0 & 7.7 & 10.3 & 6 \\
\hline 5.04 & 1.53 & 5.13 & 7.02 & 5.20 & 4.73 & 11.5 & 7.3 & 10.7 & 11.3 & 15.0 & 13.3 & 7 \\
\hline 4.76 & 7.21 & 6.66 & 4.73 & 2.52 & 4.36 & 8.7 & 9.0 & 6.3 & 10.7 & 8.7 & 9.0 & 8 \\
\hline 4.85 & 6.03 & 6.66 & 7.23 & 3.61 & 3.21 & 8.4 & 9.7 & 7.3 & 9.3 & 7.0 & 8.7 & 9 \\
\hline 4.01 & 1.53 & 1.15 & 7.23 & 4.04 & 3.06 & 6.9 & 10.3 & 6.7 & 7.7 & 5.7 & 4.3 & 10 \\
\hline 6.03 & 6.56 & 6.66 & 6.08 & 7.55 & 4.36 & 8.7 & 12.0 & 9.7 & 10.0 & 8.0 & 4.0 & 11 \\
\hline 4.27 & 5.69 & 3.46 & 6.51 & 5.00 & 2.52 & 9.9 & 10.3 & 11.0 & 8.3 & 11.0 & 8.7 & 12 \\
\hline 5.19 & 5.51 & 2.65 & 6.56 & 4.93 & 6.93 & 9.1 & 12.3 & 8.0 & 11.0 & 6.3 & 8.0 & 13 \\
\hline 5.35 & 3.06 & 9.29 & 2.89 & 5.69 & 5.03 & 9.3 & 5.3 & 11.7 & 9.3 & 8.7 & 11.3 & 14 \\
\hline 5.26 & 6.08 & 4.62 & 1.53 & 1.00 & 6.66 & 9.3 & 7.0 & 7.3 & 7.3 & 16.0 & 8.7 & 15 \\
\hline 4.62 & 0.58 & 7.51 & 6.00 & 4.93 & 1.73 & 11.3 & 11.3 & 9.7 & 12.0 & 14.7 & 9.0 & 16 \\
\hline 4.03 & 3.21 & 4.58 & 4.16 & 2.52 & 3.46 & 6.9 & 3.3 & 7.0 & 8.7 & 10.3 & 5.0 & 17 \\
\hline 5.01 & 5.57 & 2.52 & 7.81 & 1.15 & 7.23 & 11.1 & 9.0 & 9.3 & 11.0 & 13.7 & 12.3 & 18 \\
\hline
\end{tabular}




$$
\text { جدول ^- متوسط سه ساله صفات مهم زراعى زنوتيِّاى گندم نان }
$$

Table 8. Three years average for agronomic traits of wheat genotypes

\begin{tabular}{|c|c|c|c|c|}
\hline $\begin{array}{c}\text { زنوتي" } \\
\text { Genotype }\end{array}$ & تعداد روز تا ظهور سنبله & $\begin{array}{l}\text { ارتفاع بوته (سانتى متر) } \\
\text { Plant height (cm) }\end{array}$ & $\begin{array}{c}\text { تعداد روز تا رسيدن دانه } \\
\text { Days to maturity }\end{array}$ & $\begin{array}{c}\text { وزن هزاردانه(گرم) } \\
\text { Thousand kernel } \\
\text { weight (gram) }\end{array}$ \\
\hline 1 & 124 & 77 & 160 & 35 \\
\hline 2 & 125 & 84 & 162 & 33 \\
\hline 3 & 126 & 83 & 162 & 32 \\
\hline 4 & 126 & 86 & 162 & 33 \\
\hline 5 & 123 & 80 & 161 & 32 \\
\hline 6 & 127 & 76 & 163 & 32 \\
\hline 7 & 126 & 84 & 163 & 34 \\
\hline 8 & 126 & 82 & 163 & 33 \\
\hline 9 & 128 & 84 & 163 & 34 \\
\hline 10 & 125 & 79 & 162 & 34 \\
\hline 11 & 126 & 77 & 162 & 33 \\
\hline 12 & 126 & 77 & 161 & 31 \\
\hline 13 & 126 & 81 & 161 & 33 \\
\hline 14 & 127 & 79 & 162 & 34 \\
\hline 15 & 125 & 80 & 162 & 32 \\
\hline 16 & 127 & 82 & 162 & 35 \\
\hline 17 & 126 & 82 & 162 & 35 \\
\hline 18 & 127 & 82 & 164 & 34 \\
\hline
\end{tabular}

\section{References}

Akbarpour, O.A., Dehghani, H., Sorkheh Lalelu, B. and Kang, M.S. (2016). A SAS macro for computing statistical tests for two-way table and stability indices of nonparametric method from genotype-by-environment interaction. Acta Scientiarum Agronomy, 38(1): 35-50.

Akcura, M. and Kaya, Y. (2008). Nonparametric stability methods for interpreting G $\times E$ interaction of bread wheat genotypes (Triticum aestivum L.). Genetic and Molecular Biology, 31(4): 906-913.

Annicchiarico, P. (2002). Genotype $\times$ environment interactions: challenges and opportunities for plant breeding and cultivar recommendations. FAO Plant Production and Protection Paper No. 174, FAO, Rome.

Baenziger, P.S., R.A. Graybosch, I., Dweikat, S.N., Wegulo, G.L. and Hein Eskridge, K.M. (2008). Outstanding in their field: the phenotype of the 21st century plant breeder. In: Appels R., Eastwood R., Lagudah E., Langridge P., Mackay M., and McIntyre L. (eds) .Proc. 11th International Wheat Genetics Symposium. August $24-29$, Brisbane, Australia. http://ses.library.usyd.edu.au/ bitstream/2123/3325/ 1051. pdf.

Baenziger, P.S., Russell, W.K., Graef, G.L. and Campbell, B.T. (2006). Improving lives: 50 years of crop breeding, genetics and cytology (C-1). Crop Science, 46: 2230-2244.

Barnabas, B., Jager, K. and Feher, A. (2008). The effect of drought and heat stress on reproductive process in cereals. Plant Cell Environment, 31:11-38

Blum, A. (2011). Plant Breeding for Water-Limited Environments. Breeding Considerations and Strategies. Springer, New York Dordrecht Heidelberg, London U.K.

Chen, S. and M. Ravallion. (2007). Absolute poverty measures for the developing world, 19842004. Proceeding of National Academic Science (USA), 104:16757-16762.

Cullis, B.R., Smith, A., Hunt, C. and Gilmour A. (2000). An examination of the efficiency of Australian crop evaluation programmes. Journal of Agricutural Science, 135:213-222.

Farshadfar, E., Sabaghpour, S.H. and Zali, S.H. (2012). Comparison of parametric and nonparametric stability statistics for selecting stable chickpea (Cicer arietinum L.) genotypes under diverse environments. Australian Journal of Crop Science, 6(3): 514-524.

Flores, F., Moreno, M.T. and Cubero, J.I. (1998). A comparison of univariate and multivariate methods to analyze $\mathrm{G} \times \mathrm{E}$ interaction. Field Crop research, 56: 271-286.

Fox, D. N. and Rosielle, A. (1982). Reducing the influence of environmental main effects of plant breeding environments. Euphytica, 31: 645-656.

Fox, P.N., Skovmand, B., Thompson, B.K. and Braun, H.J. (1990). Yield and adaptation of hexaploid spring triticale. Euphytica, 47(1): 57-64. 
Francis, T.R. and Kannenberg, L.W. (1978). Yield stability studies in short season maize. descriptive method for grouping genotypes. Canadian Journal of Plant Science, 58:1026-1034.

Guo, T.C., Feng, W. and Zhao, H.J. (2004). Photosynthetic characteristics of flag leaves and nitrogen effects in two winter wheat cultivars with different spike type. Acta Agronomica Sinica, 30: $115-121$

Hernandez, C.M., Crossa, J. and Castillo, A. (1993). The area under the function: an index for selecting desirable genotypes. Theoretical and Applied Genetics, 87: 409-415.

Hernandez, J.A., Escobar C. and Creissen G. (2004). Role of hydrogen peroxide and the redox state of ascorbate in the induction of antioxidant enzymes in pea leaves under excess light stress. Functional Plant Biology, 31: 359-368.

Huehn, M. (1990). Nonparametric measures of phenotypic stability. Part 1: Theory. Euphytica, 47: 189-194.

Kang, M.S. (2004). Breeding: Genotype by Environment Interaction. In: Encyclopedia of Plant and Crop Science, Goodman, R.M. (Ed.). Marcel Dekker, New York, pp: 218-221.

Kang, M.S. (1993). Simultaneous selection for yield and stability in crop performance trials: Consequences for growers. Agronomy Journal, 85: 754 - 757.

Kaya, Y. and Ozer, E. (2014). Parametric stability analyses of multi-environment yield trials in triticale (Triticosecale Wittmack). Genetika, 46(3): 705-718.

Kaya, Y. and Taner, S. (2003). Estimating genotypic ranks by nonparametric stability analysis in bread wheat (Triticum aestivum L.). Journal of Central European Agricultural, 4: 47-53.

Kaya, Y. and Turkoz, M. (2016). Evaluation of genotype by environment interaction for grain yield in durum wheat using non-parametric stability statistics. Turkish Journal of Field Crops, 21(1): 5159.

Ketata, H. (1988). Genotype by environment interaction. ICARDA. Proceeding of biometrical techniques for cereal breeders. ICARDA, Aleppo, Syria.

Kilic, H., Akcura, M. and Aktas, H. (2010). Assessment of parametric and non-parametric methods for selecting stable and adapted durum wheat genotypes in multi-environments. Notulae Botanicae Horti Agrobotanici Cluj-Napoca, 38 (3): 271-279.

Kosina, P., Reynolds, M.P., Dixon, J. and Joshi, A. (2007). Stakeholder perception of wheat production constraints, capacity building needs and research partnerships in the developing countries. Euphytica. 157: 475-483.

Lantican M.A., Dubin, M.J. and Morris M.L. (2005). Impacts of International Wheat Breeding Research in the developing world, 1988-2002. CIMMYT, Mexico.

Lin, C.S. and Binns, M.R. (1988). A superiority measure of cultivar performance for cultivar $\mathrm{x}$ location data. Canadian Journal of Plant Science, 68: 193-198.

Martin, J. and Alberts, A. (2004). A comparison of statistical methods to describe x environment interction and yield stability in multlocation Maize trials. Thesis presented in accordance with the requirements for the degree Magister Scientiae Agriculturae in the Faculty of Agriculture, Department of Plant Sciences (Plant Breeding) at the University of the Free State.

Mohammadi M., karimizadeh R., Hosseinpour, T., Falahi H.A., Khanzadeh H., Sabaghnia N., Mohammadi P., Armion M. and Hosni, M.H. (2012). Genotype $\times$ Environment Interaction and Stability Analysis of Seed Yield of Durum Wheat Genotypes in Dryland Conditions. Notulae Scientia Biologicae, 4 (3), 57-64.

Mohammadi M., Sharifi, P. and Karimizadeh, R. (2014). Stability Analysis of Durum Wheat Genotypes by regression parameters in Dryland Conditions. ACTA Universitatis Agriculturae et Silviculturae Mendeliane Brunensis, 62(5): 1049-1056.

Mohammadi M., Karimizadeh, R., Sabaghnia N. and Shefazadeh, M.K. (2013). Estimating genotypic ranks by several nonparametric stability statistics in Barley (Hordeum vulgare L.). Yuzuncu Yil University Journal of Agricultural Sciences, 23(2): 57-65.

Mortazavian, S.M.M. and Azizzinia, S.H. (2014). Nonparametric stability analysis in multienvironment trial of canola. Turkish Journal of Field Crops, 19(1): 108-117.

Nassar, R. and Huhn, M. (1987). Studies on estimation of phenotypic stability: Test of significance for non- parametric measures of phenotypic stability. Biometrics, 43: 45-53. 
Neil C. Turner A,B,D, Feng-Min Li C., You-Cai Xiong C., Kadambot, H.M., and Siddique, B. (2011). Climate change and agricultural ecosystem management in dry areas. Crop and Pasture Science, 62: 1-11.

Ortiz, R., Braun, H.J., Crossa, J., Crouch, J.H., Davenport, G., Dixon, J., Dreisigacker, S., Duveiller, E., He, Z., Huerta, J., Joshi, A.K., Kishii, M., Kosina, P., Manes, Y., Mezzalama, M., Morgounov, A.I., Murakami, J., Nicol J., Ortiz Ferrara, G., Iva'n Ortiz-Monasterio J., Payne, T.S., Javier, Peña R., Reynolds, M.P., Sayre ,K.D., Sharma, R.C., Singh, R.P., Wang J., Warburton M, Wu, H. and Iwana, M. (2008). Wheat genetic resources enhancement by the International Maize and Wheat Improvement Center (CIMMYT). Genetic Resource and Crop Evolution, 55:1095-1140.

Passioura, J.B. (2007). The drought environment: physical, biological and agricultural perspectives. Journal of Experimental Botany, 58: 113-117.

Plaisted, R.L. (1960). A shorter method for evaluating the ability of selections to yield consistently over locations. American Potato Journal, 37: 166-172.

Plaisted, R.L. and Peterson, L.C. (1959). A technique for evaluating the ability of selections to yield consistently in different locations or seasons. American Potato Journal, 36: 381-385.

Roemer, T. (1917). Sind die Ertragsreichen Sorten Erteragssichers? Mitt.DLG. 32: 87-89.

Roozeboom, K.L., Schapaugh, W.T., Tuinstra, M.R., Vanderlip, R.L., and Milliken, G.A. 2008. Testing wheat in variable environments: genotype environment, interaction effects, and grouping test locations. Crop Science, 48:317-330.

SAS Institute. (2000). The SAS system for windows. Released 8.01, SAS Inst. Inc., Cary, NC.

Shukla, G.K. (1972). Some statistical aspects of partitioning genotype-environment components of variability. Heredity, 29 (2): 237-245.

Thennarasu, K. (1995). On certain non-parametric procedures for studying genotype -environment interactions and yield stability. New Dehli, IN: PJ School; Iari. Akcura, M., Kaya, Y. (2008). Nonparametric stability methods for interpreting $G \times E$ interaction of bread wheat genotypes (Triticum aestivum L.). Genetic and Molecular Biology, 31(4): 906-913.

Tester M. and Langridge, P. (2010). Breeding Technologies to Increase Crop Production in a Changing World. Science, 327: 818-822.

Von Braun, J. (2007). The world food situation: new driving forces and required actions. International Food Policy Research Institute, IFPRI's Bi-Annual Overview of the World Food Situation presented to the CGIAR Annual General Meeting, Beijing, December 3, 2007, China.

Wricke, G. (1962). Uber eine methode zur erfassung der ökologischen streubreite in feldversuchen. Zeitschrift für Pflanzenzüchtung, 47: 92-96.

Yang, J., Sears, R.G., Gill, B.S. and Paulsen, G.M. (2002). Genotypic differences in utilization of assimilate sources during maturation of wheat under chronic heat and heat shock stresses. Euphytica, 125: 179-188.

Zali, H., Farshadfar, E. and Sabaghpour, S.H. (2011). Non-parametric analysis of phenotypic stabilityin chickpea (Cicer arietinum L.) genotypes in Iran. Crop Breeding Journal, 1(1): 89-100.

Zarei Soltankohi, M. and Farshadfar, M. (2015). Evaluation of genotype $\times$ environment interaction in landraces of common wheat using non-parametric stability indicators. Biological Forum-An International Journal, 7(1): 945-950. 


\title{
Use of Parametric and Non-Parametric Methods for Genotype $\times$ Environment Interaction Analysis in Bread Wheat Genotypes
}

\author{
Mohtasham Mohammadi ${ }^{1, *}$, Rahmatollah Karimizadeh², Tahmaseb Hosseinpour ${ }^{3}$, \\ Hasan Ghojogh ${ }^{4}$, Kamal Shahbazi ${ }^{5}$ and Peyman Sharifi ${ }^{6}$
}

1- Professor, Dryland Agricultural Research Institute, Agricultural Research, Education and Extension Organization, (AREEO), Gachsaran, Iran

2- Assistant Professor, Dryland Agricultural Research Institute, Agricultural Research, Education and Extension Organization, (AREEO), Gachsaran, Iran

3- Assistant Professor, Seed and Plant Research Department, Lorestan Agricultural and Natural Resources, Research and Education Center, Agricultural Research, Education and Extension Organization, AREEO, Khoramabad, Iran

4- Lecture, Seed and Plant Research Department, Golestan Agricultural and Natural Resources, Research and Education Center, Agricultural Research, Education and Extension Organization, AREEO, Gonbad, Iran

5- Lecture, Seed and Plant Research Department, Ardabil Agricultural and Natural Resources, Research and Education Center, Agricultural Research, Education and Extension Organization, AREEO, Moghan, Iran

6- Associate Professor, Department of Agronomy and Plant Breeding, Rasht Branch, Islamic Azad University, Rasht, Iran

(Received: September 4, 2016 - Accepted: August 21, 2017)

\begin{abstract}
Breeding of adapted and variation germplasm can be a main element for strength of research political in stable agricultture system. This is achived by targeting variety selection onto different growing environments under natural heat and drought stresses. To realize this, breeding programs usually undertake a rigorous genotypes performance evaluation across locations and years mostly at the final stage of variety development process. More accurate selection of wheat genotypes requires reducing environmental effects for explaining of their genetic potential with appropriate analysis of genotype $x$ environment. In this research, 18 improved bread wheat genotypes were planted in randomized compelet block design with 4 replications in Gachsaran, Khoramabad, Gonbad, Moghan and Ilam stations during three years (2011-2014). Simple and combined analysis variance were done on grain yield data. Due to significant interaction effects for Year $\times$ locatin and genotype $\times$ year $\times$ locatin, yield stability of considered genotypes were analysed using some parameteric and nonparametric methods. Obtained results showed genotypes no. 10 and 17 with 3107 and $3028 \mathrm{~kg} / \mathrm{ha}$ had the highest grain yield. Based on parametric statistics: $\mathrm{CV}_{\mathrm{i}}, W_{i}^{2}, \sigma_{i}^{2}, \theta_{i}$,, $\mathrm{MS}_{\mathrm{Y} / \mathrm{L}}$ and MSPI and non-paramertric statistics: $S_{i}^{(2)}, S_{i}^{(3)}, S_{i}^{(6)}$, Top, Mid, Low', R-Sum, and SDR, G10 had more yield stability. More over, G12 and G17 showed suitable yiled stability among high production genotypes. Earliness Genotypes 10 and 17 lines had optimum plant height and partially high thousand kernel weight.
\end{abstract}

Keywords: Adaptaion, Breeding, Drought, Dryland, Heat, Stability

\footnotetext{
* Corresponding Author, E-mail: m-mohammadi@areeo.ac.ir
} 